\title{
Endocrinology and Metabolism Has Been Indexed in MEDLINE: A Major Achievement
}

\author{
Won-Young Lee \\ Editor-in-Chief of Endocrinology and Metabolism
}

Endocrinology and Metabolism (EnM, pISSN 2093-596X, eISSN 2093-5978, https://www.e-enm.org), which is the official journal of the Korean Endocrine Society (http://www.endocrinology.or.kr), was indexed in MEDLINE in March 2019. I am delighted to share this news with the readers, authors, reviewers, and editors of EnM. Specifically, the Literature Selection Technical Review Committee (LSTRC) of MEDLINE informed me on March 22, 2019 that EnM has been accepted for inclusion in MEDLINE. In my opinion, this is a major achievement in our journey toward becoming a renowned international journal in the field of endocrinology and metabolism.

A National Institutes of Health (NIH)-chartered advisory committee, the LSTRC evaluates and recommends journals for MEDLINE. The LSTRC considers the quality of the scientific content of a journal, including its originality. A special feature of MEDLINE is that it uses Medical Subject Headings (MeSH) to index citations.

We, the editors of EnM, devoted ourselves to the goal of making EnM a MEDLINE journal in order to establish it as a significant platform for the exchange of up-to-date knowledge in the field of endocrinology. Therefore, I would like to present a brief summary of the recent progress that EnM has made.

We added the credentials and affiliations of the editorial board members to our website, including their Researcher IDs and Open Researcher and Contributor ID (ORCID) identifiers [1]. We also improved the editorial quality of EnM by implementing a high-quality system for English-language editing and statisti- cal review. Every manuscript is published after close examination by statistical editors, manuscript editors, and a professional English editing company (Compecs Inc., Seoul, Korea). We consolidated our ethics regulations and have made efforts to comply with all ethical guidelines recommended by the International Committee of Medical Journal Editors (ICMJE). Editorial policies and best practices are described on the EnM homepage and are actively implemented. The acceptance rate of unsolicited manuscripts has been lowered to $44 \%$ for the most recent 2 years. We have published increasingly more high-quality articles, such as randomized controlled trials, meta-analyses, and systemic reviews. We expect EnM to be essential reading for policy-makers who are interested in health problems that are still incompletely understood or environmental health threats such as endocrine disruptors, as we are publishing important articles in this field $[2,3]$.

The scope of our journal has been widened to include authors from throughout the world. Articles by authors from 32 countries on 6 continents have been published in EnM in recent 6 years, and investigators from 51 countries have submitted manuscripts. EnM has shown an steep increase in Scimago Journal Rank (SJR) which was 0.766 in 2016, and 1.12 in 2017. The editorial board of EnM includes world-renowned scientists who have published papers in major journals such as Cell, Nature, and NEJM as principal authors, and many of them are editorsin-chief of other major endocrine journals.

EnM has been indexed in the EBSCO database since 2012,
Received: 8 May 2019, Accepted: 14 May 2019

Corresponding author: Won-Young Lee

Division of Endocrinology and Metabolism, Department of Internal Medicine, Kangbuk Samsung Hospital, Sungkyunkwan University School of Medicine, 29 Saemunan-ro, Jongno-gu, Seoul 03181, Korea

Tel: +82-2-2001-2579, Fax: +82-2-2001-2049, E-mail: drlwy@hanmail.net
Copyright $(2019$ Korean Endocrine Society

This is an Open Access article distributed under the terms of the Creative Commons Attribution Non-Commercial License (http://creativecommons.org/ licenses/by-nc/4.0/) which permits unrestricted non-commercial use, distribution, and reproduction in any medium, provided the original work is properly cited. 
and is also indexed in ScienceCentral (http://e-sciencecentral. org), which provides free full-text archives of scientific journals published by members of the Korean Federation of Science and Technology Societies. The ScienceCentral database provides translations into 80 other languages in collaboration with Google Translate.

Our triennial report presents more details on the improvements that EnM has made over the last 3 years [4]. To increase the readability of EnM, we have started uploading audio slides of the articles made by the authors. We have also started providing audio summaries to briefly introduce the contents of each issue. Many excellent research papers that were supported by U.S. NIH grants have been published in EnM.

Through these efforts, it will be possible for EnM to progress toward becoming a renowned international journal, and I am very pleased with these advances. I hope that EnM will continue to advance, enabling it to make further contributions to both basic and clinical research in the field of endocrinology.

The next goal of EnM is to be indexed in SCI(E) and to become a leading journal in the field of endocrinology in the AsiaPacific region and around the globe. By doing so, we hope to disseminate valuable data from Asian countries among international readers, which would be meaningful for global scientific progress. I would like to express my sincere gratitude to all the editorial board members of EnM, all members of the Korean Endocrine Society, and all international contributors. The achievement of being indexed in MEDLINE is rooted in their efforts. I firmly believe that EnM will continue to progress to become a world-class journal, and once more express my gratitude to all.

\section{CONFLICTS OF INTEREST}

No potential conflict of interest relevant to this article was reported.

\section{ORCID}

Won-Young Lee https://orcid.org/0000-0002-1082-7592

\section{REFERENCES}

1. Im J. Applying Open Researchers and Contributors ID in scholarly journals. Sci Ed 2015;2:28-31.

2. Kim KJ, Ha S, Lee YH, Noh JH, Kim SG. The status and distinct characteristics of endocrine diseases in North Korean articles published between 2006 and 2015. Endocrinol Metab (Seoul) 2018;33:268-72.

3. Lee DH. Evidence of the possible harm of endocrine-disrupting chemicals in humans: ongoing debates and key issues. Endocrinol Metab (Seoul) 2018;33:44-52.

4. Rhee EJ, Jang HY, Lee WY. Triennial report of Endocrinology and Metabolism, 2015 to 2017. Endocrinol Metab (Seoul) 2018;33:195-201. 